\title{
INOVAÇÃO TECNOLÓGICA COMO INSTRUMENTO PARA O DESENVOLVIMENTO NO BRASIL
}

\section{TECHNOLOGICAL INNOVATION AS AN INSTRUMENT FOR DEVELOPMENT IN BRAZIL}

\author{
${ }^{1}$ Melina Ferracini de Moraes
}

\begin{abstract}
RESUMO
O presente artigo tem como pano de fundo a questão da pesquisa e desenvolvimento de Inovação Tecnológica no Brasil diante do atual contexto mundial econômico. Ao mesmo tempo em que enfrenta o problema da dependência econômica de outros países, o Brasil tem de lidar internamente com uma desigualdade social, cultural e política que dificulta a arrancada desenvolvimentista que tanto precisa. A solução apresentada consiste na endogeneização do mercado, conforme artigos 218 e 219 da Constituição Federal, bem como o fortalecimento dos centros de decisão, tendo no Estado o ator principal dessas mudanças.
\end{abstract}

Palavras-chave: Desenvolvimento, Inovação tecnológica, Endogeneização do mercado, Pesquisa tecnológica, Celso furtado

\begin{abstract}
This article is based on the question of research and development of technological innovation in Brazil and how it has been unwinding in front of the current economic global context. While facing the problem of economic dependence on other countries, Brazil has to internally deal with social inequality, cultural and policy that hinders the developmental run that needs a lot. The solution presented is the market endogenization as articles 218 and 219 of the Federal Constitution says and the strengthening of decision-making centers, being the state the main actor of these changes.
\end{abstract}

Keywords: Development, Technological innovation, Market endogenization, Technological research, Celso furtado

\footnotetext{
${ }^{1}$ Mestre em Direito Político e Econômico pela Universidade Presbiteriana Mackenzie, São Paulo, (Brasil). E-mail: melina_ferracini@hotmail.com
} 


\section{INTRODUÇÃO}

A manipulação de Tecnologia de Informação e Comunicação passou a ser fator relevante para as grandes empresas no mercado nacional e internacional devido à nova ordem econômica mundial e à demanda globalizada.

Essa é a principal fator de definição do desenvolvimento e subdesenvolvimento de uma nação. O país é considerado central, quando sua economia globalizada, consegue firmar- se no mercado mundial como exportar de produtos e tecnologia. Por outro lado, os países subdesenvolvidos são caracterizados, primordialmente, pela tecnologia que importam, além de outros produtos e serviços.

Mas nem sempre o desenvolvimento econômico, pautado no ajuste tecnológico, acompanha o desenvolvimento social de um país, ou seja, nem sempre o avanço nas áreas de pesquisa e tecnologia representam a geração de mais empregos ou mais oportunidades aos indivíduos.

Além de problemas como educação, elevada taxa de desemprego, falta de acesso a recursos básicos (moradia, salário digno etc.) e de investimento em infraestrutura, outra questão surge: como ampliar a barreira tecnológica e superar o subdesenvolvimento?

O presente trabalho tem por objetivo analisar uma possível solução para desigualdades econômicas e sociais de nosso país, através da centralização dos centros de decisão e endogeineização do mercado interno, estimulando para tanto as inovações tecnológicas.

Através do método hipotético-dedutivo, a pesquisa visa analisar como alguns países alcançam elevados níveis de produção e acumulação de riquezas enquanto outros ainda engatinham no cenário tecnológico e produtivo, na teia capitalista.

O país subdesenvolvido, portanto é aquele que, comparado aos países que já conseguiram atingir elevado nível do desenvolvimento das suas forças produtivas, em determinado momento histórico apresenta-se economicamente fragmentado, com deficiente unidade na vida econômica (atividade econômica deficientemente integrada), com mercados regionais mal reunidos e com um mercado nacional em situação de acentuada dependência em relação ao mercado mundial, com fraca concentração na produção industrial e agrícola, com formas atrasadas nas relações de produção (formas pré-capitalistas) um baixo grau de desenvolvimento no antagonismo entre as classes, bem como baixo grau de desenvolvimento das atividades associativas. Além destes, outros elementos costumam caracterizar o país subdesenvolvido: taxas elevadas de natalidade e de mortalidade, baixa capacidade nos serviços 
de saúde pública, baixo uso de energia por habitante, elevado índice de analfabetismo, baixa mobilidade de população e rigidez da estrutura social (KONDER, 2009, p.226).

Neste trabalho será analisado como a inovação pode ser fator construtivo ou até mesmo destrutivo dentro dos países que adotaram as práticas neoliberais. Observa-se ainda, a inadaptabilidade dos países, considerados subdesenvolvidos, nesse processo de inovação tecnológica, que não conseguem alcançar de maneira micro ou macro uma evolução efetiva de seus padrões sociais e econômicos.

Nesse cenário encontramos o Brasil, que avançou de forma considerável, quando da organização de parques industriais (clusters), incentivo a pesquisas na área de tecnologia e ciência com a Lei de Inovação, bem como de programas sociais de incentivo a educação e redução de pobreza. No entanto, continua no ranking de países considerados periféricos por não conseguir superar o subdesenvolvimento, visto que ainda vivencia a heterogeneidade tecnológica entre setores, ou seja, a falta de correspondência entre a disponibilidade de recursos, fatores e as combinações destes requeridas pela tecnologia que está sendo absorvida. (FURTADO, 2009, p.174).

Passemos a análise dos pontos principais da temática apresentada, sem a pretensão de esgotar a discussão do tema proposto.

\section{INOVAÇÃO TECNOLOGICA E NEOLIBERALISMO}

Dentre as várias concepções de inovação (sociológica, mercadológica, etc.) aquela que mais se compatibiliza com esta discussão é aquela inserta no Manual de Oslo, como sendo “implementação de um produto (bem ou serviço), novo ou significativamente melhorado, ou um processo, ou um novo método de marketing, ou um novo método organizacional nas práticas de negócio, na organização local de trabalho ou nas relações de trabalho" (OCDE, 2005 p.55).

Por uma análise mais restrita observa-se que a inovação integra um conjunto de métodos e práticas, bem como implementação de produtos que são capazes de mudar um conjunto econômico vigente. E sendo assim, a inovação é a base para compreensão da dinâmica entre os países desenvolvidos e subdesenvolvidos, e, portanto, da economia neoliberal, ou capitalista.

Vários pensadores surgiram no início do século XX buscando explicar o embricamento entre a inovação tecnológica e as relações entre países na economia mundial. Nesse caminho, surge Schumpeter esclarecendo que o capitalismo, que é pro natureza, uma forma ou método 
de transformação econômica, tem como impulso fundamental a inovação. (SCHUMPETER,1961, p.110).

Como a sociedade capitalista trabalha com o modelo da reprodução e de acumulação, o que tem ocorrido é o monopólio de importantes inovações por países dominantes. Dessa forma, o espirito de empreendedorismo dos capitalistas e a proteção da propriedade (alicerce do capitalismo) são seus grandes responsáveis pelo desenvolvimento em larga e rápida escala, conquanto o oposto também seja verificado com muita estagnação e atraso.

Nesse sentido, as relações existentes entre infraestrutura (forças produtivas que geram acumulação de capital e tecnologia) e a superestrutura (fatores ideológicos) influenciam diretamente o processo de desenvolvimento e, dessa interação, se define a forma pela qual será utilizado o excedente econômico, que por sua vez atua de forma cíclica sobre a acumulação de capital e a tecnologia.

Dentro dessa perspectiva de dominação e de dependência de inovação tecnológica entre países, pode-se afirmar que há países que se industrializaram e se tornaram globais no século XIX, denominados "países do Atlântico Norte"; e aqueles que se industrializaram tardiamente, no século XX, os chamados "países restos". E, por fim, aqueles que ainda não se industrializaram os denominados "países resquícios" (ASDEM,2009, p.47-55).

Segundo a autora, os países "resto", para competir tecnologicamente com o primeiro grupo, adotaram diferentes tipos de estratégia de desenvolvimento para suas empresas classificando-os em: "independentes" e "integracionistas". Os “independentes" representam o grupo que escolheu o caminho de crescimento a partir do fortalecimento das capacidades e da autonomia tecnológica de suas empresas nacionais (China, Índia, Coréia e Taiwan, por exemplo). Os "integracionistas", a seu turno, adotaram o caminho de crescimento a partir da importação de tecnologias e da obediência às regras de conduta internacionais acerca das transferências tecnológicas - por exemplo, Brasil, Argentina, Chile, México e Turquia (BRAGA, BERCOVICI, OCTAVIANI, VASCONCELOS, 2011, p.13).

Assim, pode-se afirmar que o investimento em pesquisa de novas tecnologias é o fator determinante pela posição dominante que certos países têm sobre outros. O conhecimento transformado em pesquisa, desenvolvimento e inovação tecnológica gera produtos com alto valor agregado, decidindo os espaços ocupados pelos países e suas empresas. (BERCOVICI, OCTAVIANI, VASCONCELOS,2011, p.15).

Dentro do espaço ocupado por países que investem em tecnologia, o Brasil, acompanhado de países como Turquia e Argentina, não possui um sistema de inovação 
completo capaz de autonomamente sustentar uma econômica juntamente com seus problemas sociais.

$\mathrm{Na}$ maioria dos países "restos", caracterizados por problemas sociais, estabilidade monetária e constante crise fiscal, seus governos são constantemente pressionados a adotar receitas do Fundo Monetário Internacional para solucionar sua problemática. E assim, o investimento em conhecimento tecnológico fica sempre em segundo plano, relegando à iniciativa privada o papel fundamental na comunidade de pesquisa e desenvolvimento exatamente naquilo que o governo ou o Estado ainda não é capaz de suprir.

Pesquisa apresentada no Senado Federal brasileiro demonstra que os BRICS (grupo formado por Brasil, Rússia, Índia, China e África do Sul criado para obter maior influência geopolítica) tem se valido da iniciativa privada para pesquisa com inovação tecnológica:

Figura 1 - Gráfico demonstrando a proporção de investimentos em pesquisa e desenvolvimento no Mundo.

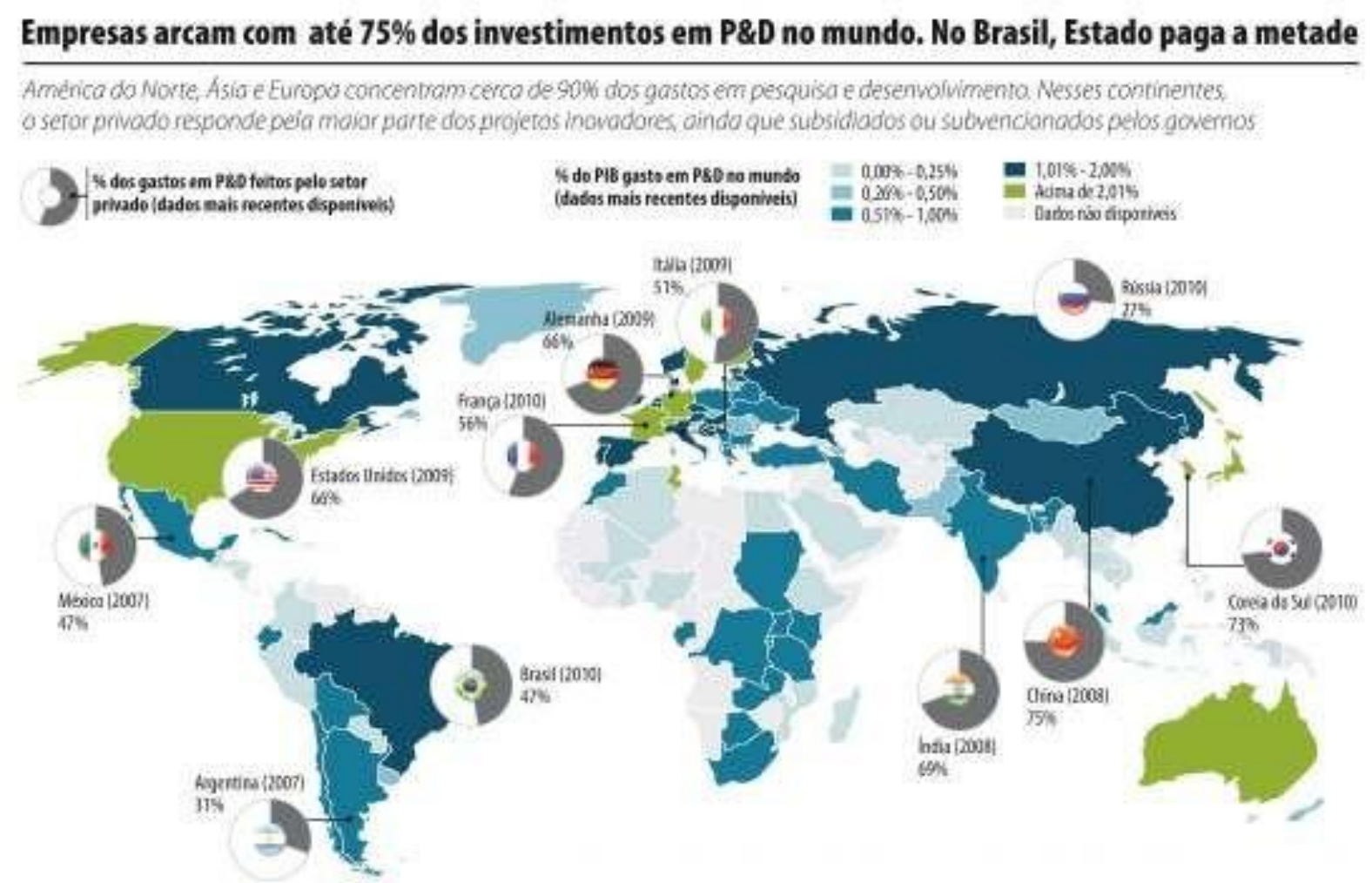

Fonte: Em Debate: Revista de Audiência Pública do Senado Federal, apud TEIXEIRA, 2012.

Ao se comparar a proporção em relação ao PIB do investimento em pesquisa e desenvolvimento no Brasil com os números de nações da Organização para a Cooperação e Desenvolvimento Econômico (OCDE) com outros países da América Latina e dos chamados "BRICS", percebe-se que nosso país só está acima de México, Argentina, Chile, África do Sul e Rússia - ficando muito distante de China e Coreia do Sul, por exemplo, nações 
que iniciaram muito recentemente o salto de desenvolvimento industrial. A China tornou-se, em 2011, o segundo maior investidor mundial em pesquisa e desenvolvimento.

O Brasil se destaca pelo volume de investimento em pesquisa feito pela iniciativa privada e os seus $0,55 \%$ do PIB (produto interno bruto) aplicados pelas empresas privadas, que está longe de países como a Coréia do Sul $(2,68 \%)$ e da China $(1,22 \%)$.

Por outro lado, quando se fala em investimentos públicos em pesquisa e desenvolvimento, o Brasil está na média de nações consideradas desenvolvidas. O 0,61\% do PIB brasileiro está próximo ao percentual investido, de $0,69 \%$ pelo conjunto de países da OCDE.

Portanto, com a ascensão do neoliberalismo a partir da década de 1970, uma nova ordem econômica e financeira eclodiu. Essa nova ordem, valorizando a perspectiva capitalista de concorrência de mercado e inovação tecnológica que atendesse o aquele, produziu uma disparidade entre países. Aqueles que conseguiram de uma forma rápida e eficaz desenvolver seu processo de industrialização e investimento em pesquisa, destacam-se no cenário mundial como fornecedores de produtos e serviços a outros países (restos ou resquícios).

Nesse contexto, o Brasil está inserido em um processo incompleto no que se refere a investimento em inovação tecnológica, porque o próprio Estado elege como metas prioritárias de gastos outros setores da economia o que restringe o campo de atuação em pesquisa e desenvolvimento a grupos empresariais e comunidade acadêmica.

\section{BRASIL: DESAFIO DA INOVAÇÃO TECNOLÓGICA.}

É certo que na disputa por melhores condições no mercado, e, por consequência, uma melhor colocação no ranking de países que investem em desenvolvimento e tecnologia, o Brasil vem procurando incentivar a pesquisa em inovação tecnológica. Para se entender o movimento de industrialização e tentativa de superação do subdesenvolvimento do Brasil, bem como e incentivo à pesquisa, necessário se faz um desenho da inovação no nosso ordenamento jurídico.

O Brasil-colônia caracterizou-se por uma fase de extrema dependência econômica de nosso país com Portugal. Os colonizadores não tinham a intenção de fomentar qualquer tipo de progresso em nosso território, ao contrário, a intenção era aproveitar-se de todos os bens (matéria prima) para obtenção de lucro.

Algum lampejo de desenvolvimento começou a surgir por volta de 1930, com a implantação de plano e meta de desenvolvimento pelo governo, bem como o incentivo a indústrias e benefícios à massa de trabalhadores da zona urbana. 
A partir daí pode-se afirmar que a industrialização sustentou o desenvolvimentismo em várias versões: a versão democrática, nacionalizante e popular, na versão autoritária, internacionalizante e antipopular e no período de tempo ocorrido entre elas, caracterizado por verdadeiras "fugas para frente", sob a forma de modernizações conservadoras (OCTAVIANI, 2008, p.06).

A década de 50, especialmente, foi desenhada por uma proposta de crescimento acelerado com base na oferta de emprego, interiorização do mercado interno e expansão da infraestrutura e agronegócio. A política econômica valorizava a produção nacional, incentivando inclusive a substituição das importações.

O sonho desenvolvimentista sofreu ruptura com a ditadura militar implementada em nosso país em 1964. O país estava entregue a um governo autoritário e antipopular teve sua economia fortemente influenciada por conflitos entre os interesses privados nacionais (elites políticas) e internacionais, tendo como solução a estratégia de "fuga para frente".

A década de 80 restou caracterizada como período de estagnação. Após um período de intensa expansão econômica, o país ficou à deriva, sem um padrão desenvolvimentista que resolvesse o problema de superávits comerciais e redução de consumo de determinados produtos, que antes movimentavam a economia.

Com forte influência do neoliberalismo, os anos 90 trouxeram a abertura de mercado nacional forçando uma competição de âmbito mundial no mercado e também eliminando setores inteiros da economia. O dilema da inovação e internacionalização não foi resolvido.

$\mathrm{Na}$ década seguinte, a partir de 2004, inicia-se um movimento consolidado e autoconsciente de indução da capacidade inovadora da indústria aqui instalada.Com a publicação da Lei 10.973/04 (Lei de Inovação Tecnológica), vislumbrou-se um avanço no incentivo de pesquisa e desenvolvimento pautado em torno de três eixos fundamentais: a constituição de ambiente propício a parcerias estratégicas entre universidades, institutos tecnológicos e empresas; o estímulo à participação de institutos de ciência e tecnologia no processo de inovação e o estímulo à inovação da empresa.

A lei prevê o compartilhamento de infraestrutura, equipamentos e recursos humanos, públicos e privados entre o espaço público e as empresas e ainda traz dispositivo que regula a participação do pesquisador público nos processos de inovação tecnológica desenvolvidos no setor produtivo.

Dessa forma, foi possível estruturar um sistema nacional de inovação, que pode ser entendido como um como um grupo articulado de instituições dos setores público e privado (agências de fomento e financiamento, instituições financeiras, empresas públicas e privadas, 
instituições de ensino e pesquisa etc.) cujas atividades e interações geram, adotam, importam, modificam e difundem novas tecnologias, sendo a inovação e o aprendizado seus aspectos cruciais (VILLELA, 2009, p. 03).

Ou seja, o que se vislumbra é um grau de integração entre universidade, governo e setor privado, o que pode ser chamado por "Tripla Hélice” (VILLELA,2009, p. 10).

Apesar de grandes esforços realizados nesse sentido, o Brasil tem um movimento tardio na regulamentação do Sistema Nacional de Inovação devido a precarização das instituições de ensino e pesquisa, a debilidade de políticas de incentivo à inovação e a desorganização de financiamentos de longa duração. Além da baixa articulação entre entes governamentais, empresas e universidades.

Posteriormente outras leis surgiram, como a Lei do "Bem" (Lei 11.196/05) Lei 11.487/07, que detalhou o licenciamento para outorga de direitos de uso e a exploração de propriedade industrial e intelectual, bem como dispôs sobre interessantes incentivos fiscais para a inovação tecnológica. Ainda que dotada de forte carga burocrática, significou ao empresariado nacional um real incentivo na busca por pesquisa e desenvolvimento.

Assim, a forte integração entre o sistema nacional de inovação, a Constituição e a legislação infraconstitucional perseguem um único objetivo: o desenvolvimento nacional de forma a reduzir as desigualdades sociais e regionais, como bem prevê o artigo $3^{\circ}$ da Constituição.

Atualmente, não há outra forma de analisar as leis propostas e compatibilizá-las a nossa realidade econômica e social, senão sob a perspectiva dos artigos 218 e 219 da nossa Constituição, que delineiam a construção de uma ordem econômica nacional baseada na promoção e desenvolvimento da ciência e tecnologia e por consequência a proteção e incentivo ao mercado interno.

A Constituição Federal, em seus artigos 218 e 219 prevê que:

“Art. 218. O Estado promoverá e incentivará o desenvolvimento científico, a pesquisa e a capacitação tecnológicas.

$\S 1^{\circ}$ A pesquisa científica básica receberá tratamento prioritário do Estado, tendo em vista o bem público e o progresso das ciências.

$\S 2^{\mathrm{a}}$ A pesquisa tecnológica voltar-se-á preponderantemente para a solução dos problemas brasileiros e para o desenvolvimento do sistema produtivo nacional e regional.

$\S 3^{\circ} \mathrm{O}$ Estado apoiará a formação de recursos humanos nas áreas de ciência, pesquisa e tecnologia, e concederá aos que delas se ocupem meios e condições especiais de trabalho.

$\S 4^{\circ}$ A lei apoiará e estimulará as empresas que invistam em pesquisa, criação de tecnologia adequada ao País, formação e aperfeiçoamento de seus recursos humanos e que pratiquem sistemas de remuneração que assegurem ao 
empregado, desvinculado do salário, participação nos ganhos econômicos resultantes da produtividade de seu trabalho.

$\S 5^{\mathrm{a}}$ É facultado aos Estados e ao Distrito Federal vincular parcela de sua receita orçamentária a entidades públicas de fomento ao ensino e à pesquisa científica e tecnológica.

Art. 219. O mercado interno integra o patrimônio nacional e será incentivado de modo a viabilizar o desenvolvimento cultural e socioeconômico, o bemestar da população e a autonomia tecnológica do País, nos termos de lei federal".

Em primeiro plano, a análise dos artigos 218 e 219 “determinam a endogeneização da tecnologia e a homogeneização social, compondo o quadro de internalização dos centros decisórios que deve orientar toda regulação”. (OCTAVIANI, 2011).

O artigo 218 deixa claro o papel do Estado no processo de desenvolvimento científico e de pesquisa tecnológica. Ele "promoverá" e "incentivará” através de políticas públicas e instituições a promoção da pesquisa de inovação tecnológica. A atuação do Estado, não é imparcial, pois tem como o fim o progresso da ciência e o bem-estar público $\left(\S 1^{\circ}\right)$ além de buscar soluções dos problemas internos, concernentes a nossa realidade como país $\left(\S 2^{\circ}\right)$.

Além disso, fica evidente o incentivo à iniciativa privada. E nesse caso, não de forma proativa, mas de forma neutra, pois as empresas ou grandes conglomerados empresariais, bem como as universidades são os protagonistas da pesquisa e inovação.

Segundo Eros Grau:

"A tarefa de viabilizar o rompimento do processo de dependência tecnológica no qual estão embrenhadas as sociedades subdesenvolvidas é missão do Estado, ainda que a evolução tecnológica haja de ser empreendida pela empresa - não mais pelo indivíduo" (GRAU, p. 264-265).

Assim, o que se denomina endogeneização da tecnologia é a atuação estatal orientadora da produção tecnológica de forma interna e voltada para as necessidades do país.

O artigo 219 da Constituição Federal veio somar a essa ideia de endogeneização da tecnologia, pois define o alcance da ação estatal: o mercado interno. Nesse dispositivo fica evidente que o mercado interno é patrimônio nacional e deve ser funcionalizado para atingir as necessidades de nosso país. O mercado interno deve ser visto como veículo para superação do subdesenvolvimento, ou seja, deve buscar a promoção do desenvolvimento em um sentido muito mais amplo do que o econômico. É preciso considerar o aspecto social.

Muito mais do que o viés econômico, o incentivo ao mercado interno tem viés social, pois incentivar o mercado é distribuir renda e realizar políticas de bem-estar, liberando os 
efeitos de aumento de demanda que Furtado afirma terem ocorrido na virtuosa industrialização nos países desenvolvidos, ou centrais (OCTAVIANI, 2008, p.179).

Vale ressaltar que os comandos constitucionais devem ser analisados, principalmente e conjuntamente com a Lei de Inovação Tecnológica, que explicita e detalha a atuação do setor privado bem como do Estado. O aparato jurídico tem procurado acompanhar as necessidades do país em desenvolver seu próprio parque tecnológico, tanto que ao considerar o mercado interno como patrimônio nacional, o legislador busca internalizar os centros de decisão.

A par destes aspectos jurídicos e históricos mais relevantes, no que diz respeito da inovação em nosso país, ainda cabe discutir em que medida a inovação e seu aparato jurídico tem contribuído para o desenvolvimento do Brasil.

\section{CAMINHOS PARA INOVAÇÃO NO BRASIL}

Apesar da criação do aparato jurídico que favorece o crescimento interno de nosso país na área de pesquisa e inovação tecnológica, a grande dificuldade é traduzir esse desenvolvimento científico em progresso material e bem-estar social para os brasileiros.

O Brasil está longe de desconstruir a realidade de país subdesenvolvido e realizar a superação da sua condição de dependência tecnológica em relação a outros países (desenvolvidos). O primeiro passo a ser dado é a construção de um processo de endogeneização tecnológica, que implica em uma revolução do sistema educacional bem como na incorporação sistemática ao processo produtivo da inovação como mecanismo de reprodução e a ampliação do potencial social e econômico do país.

Neste sentido, dois grandes desafios são apresentados: o combate à heterogeneidade social e o combate a situação de dependência imposta ao Brasil (CABRAL,2012, p.25).

A heterogeneidade estrutural em todas as suas dimensões sempre se afirmou como um traço marcante de nossa formação econômica e social. Se considerarmos por outro ângulo, além dos aspectos macroeconômicos, ela se traduz em um país de dimensões continentais com insuficiência da infraestrutura física.

Dessa forma, o processo de industrialização e até mesmo da veiculação de um campo industrial que atenda às necessidades brasileiras encontra aí sua primeira barreira.

Se o Brasil possui diversas regiões que não tem acesso ao mínimo existencial para sobrevivência, como equalizar esse quociente populacional com o desenvolvimento de indústria e mão de obra qualificada? Esse é um dos principais desafios na implementação de pesquisa e tecnologia, bem como no processo de industrialização que satisfaça o mercado interno. 
Além disso, os incentivos e dotação orçamentária compatível com o desenvolvimento de pesquisa em inovação tecnológica nacionais ainda estão prejudicados.

Ficar adstrito às commodities sem que tais recursos sejam amplamente aproveitados pela indústria nacional é estimular que as grandes empresas atuantes no mercado mundial cumpram tal papel quanto ao investimento em inovação, levando daqui muito mais do que divisas. Nem se diga que não há demanda interna por tecnologia, pois até as transnacionais aqui instaladas reclamam a dificuldade na implantação de suas patentes para seu uso no mercado interno.

Tanto é assim, que em 31 de março do ano passado o Ministério do Desenvolvimento, Indústria e Comércio Exterior (MDIC) e a Agência Brasileira de Promoção de Exportações e Investimentos (Apex-Brasil) lançaram, em Nova Iorque, o programa Innovate in Brasil. O objetivo é atrair a instalação de Centros de Pesquisa e Desenvolvimento (P\&D) de empresas multinacionais estrangeiras, novo foco de atuação do Governo Brasileiro.

E nesse sentido ensina Furtado:

"Para desenvolver-se internamente, de forma nacional, é necessário individualizar-se. Em outras palavras, a individualização não é simples consequência do desenvolvimento. É fator autônomo. Atribui-se assim, grande importância à autonomia na capacidade de decisão, sem a qual não pode haver uma autêntica política de desenvolvimento. (...) E como o principal centro de decisão é o Estado, atribui a este o papel básico na consecução do desenvolvimento" (FURTADO, p. 216).

Para que seja possível o desenvolvimento genuíno de tecnologia nacional é importante que o Estado "promova" e "incentive" políticas públicas aos interessados em satisfazer a demanda de pesquisa tecnológica para evitar o controle direto e indireto de grupos estrangeiros nas indústrias nacionais - aí se destacando aqueles ligados à mineração e energia.

Em que pese seja um alento ao empresariado nacional, a chamada Lei do Bem ainda não é largamente utilizada no Brasil porque os requisitos para seu aproveitamento partem da péssima articulação política e estrutural dos entes responsáveis. Traduzindo: o empresariado tem que superar a forte exigência burocrática na Receita Federal e no Ministério da Ciência e Tecnologia.

Isto se dá porque vislumbrando a oportunidade de melhorar (ou propriamente inovar) seus produtos, a indústria necessita da identificação pormenorizada de seus projetos com potencial para se adequar às exigências da Lei do Bem; ter absoluto cuidado com a documentação comprobatória: plano de negócios claro e bem formatado, resumo e cronograma de projetos, razões contábeis, ordens de compra, contratos, notas fiscais, ordens de serviço interdepartamental, apontamento de 
horas por projeto, definição do escopo, amostras básicas e contabilização adequada - para, obviamente, estar preparado para a fiscalização.

Outra preocupação no campo da inovação tecnológica é o registro de patentes dos produtos e bens criados. $\mathrm{O}$ sistema de patentes e a propriedade intelectual no Brasil exerce papel importante no desenvolvimento socioeconômico nacional, pois com a divulgação de novas invenções e o seu devido registro, renova-se a dinâmica do mercado, ampliando a competitividade e a circulação de moeda dentro do próprio pais.

A lei de propriedade industrial, Lei 9.279/96, representa mais uma "fuga para frente", na medida em que dificulta o registro de patentes dentro de sua própria sistemática. As falhas na forma de definição das normas que tratam da interação entre o inventor, a universidade e os institutos de pesquisa, e o capital de risco bem como a ausência de um sistema de proteção à propriedade intelectual eficiente, que proteja os agentes inovadores e sua criação. Na maioria dos casos, esses agentes ficam à mercê de usurpadores que, na ausência de impedimento legal, inexoravelmente copiarão a invenção ou o aperfeiçoamento. O resultado é um cenário em que o agente não inova ou prefere manter suas invenções secretas, privando a sociedade e o mercado de um produto inovador e de suas importantes informações técnicas.

Uma boa notícia surgiu em janeiro deste ano: o INPI (Instituto Nacional da Propriedade Industrial) aderiu ao projeto piloto PPH (Patent Prosecution Highway) em parceria com o escritório de patentes dos Estados Unidos (United States Patent and Trademark Office USPTO), cujo objetivo é propiciar àqueles que obtenham direitos patentários no Brasil um prazo menor em relação ao atual, além de acelerar os trâmites no USPTO.

Uma empresa inovadora de qualquer setor que tem depósito ou que pretende depositar sua patente primeiramente no Brasil e tem interesse igualmente em exportar para os EUA, poderá ter o exame de patente realizado em ambos os países mais rapidamente. Ao mesmo tempo, uma empresa estrangeira que queira investir no Brasil no setor de petróleo e gás e já tenha sua patente deferida nos EUA, poderá usar o programa para acelerar o processo de concessão da mesma patente no Brasil. Mas como nem tudo são flores, estes pedidos são limitados a cento e cinquenta em cada país e o projeto só tem confirmada a duração pelos próximos dois anos (passível de prorrogação, entretanto).

E a tendência, sem iniciativas como esta de viabilizar o registro de inovações de maneira mais ágil, é que o país perpetue sua condição de dependência tecnológica com os ditos países centrais.

O desafio brasileiro nas áreas de ciência e tecnologia é o de decidir qual caminho deve ser dado à produção cientifica e tecnológica, de modo a atender os problemas e o perfil de consumo do 
próprio país. A escolha desse caminho perpassa, necessariamente, pela internalização de centros decisórios ligados a inovação e suas consequências, internas e externas. A legislação de incentivo tecnológico tentou suprir as lacunas deste processo de desenvolvimento interno, mas não foram suficientes para estimular o investimento maciço das indústrias nacionais em tecnologia e inovação.

Esse processo não significa que dentro do contexto mundial o Brasil tenha que se isolar das relações comerciais com outros países. O que se pretende é que através da internalização do centro de decisão e da industrialização, assim como políticas públicas voltadas ao desenvolvimento nacional atenda, em primeiro plano, a demanda nacional.

Tal é o principal objetivo a ser atingido para superação do subdesenvolvimento do Brasil. Ajustar a ciência e a tecnologia para responder as necessidades tecnológicas nacionais pressupõe um processo em três níveis de construção: a articulação e assimilação de tecnologias, a adaptação de tecnologias externas para demandas nacionais e a criação de novas técnicas e tecnologias (ALBUQUERQUE, 2005, p. 20).

Logo, o ator principal do desafio de implementação de pesquisa e tecnologia no país é o Estado. O Estado representado de diversas maneiras, através de políticas públicas, de agências governamentais, bancos de fomento, universidades públicas, institutos de pesquisa, dá a produção científica e tecnológica nacional (na esfera pública e privada) um caráter que possibilite em alguns aspectos combater a condição periférica apresentada sob a ótica da inovação.

\section{CONCLUSÃO}

A ordem econômica mundial e a necessidade de aprimoramento de ciência e tecnologia trouxeram a hierarquização dos países. Os países considerados desenvolvidos, com maior engajamento nas relações comerciais, atuam como exportadores de produtos e inovação tecnológica. Em contrapartida os subdesenvolvidos, em razão de todo um desencadeamento histórico e econômico, são considerados periféricos, subdesenvolvidos.

O relacionamento entre centro-periferia é o que movimenta o ideal neoliberalista, baseados nos valores como acumulação, mais valia e reprodução social.

Dentre os valores disseminados pelo capitalismo, a corrida por inovação tecnológica tem se destacado. O investimento e incentivo a pesquisa sobre tecnologia e desenvolvimento tem sido de relevante importância, principalmente para países subdesenvolvidos. Até mesmo como uma esperança para superar a situação de subdesenvolvimento e exploração do mercado interno. 
Nesse cenário, o Brasil, tem chamado a atenção pelos investimentos que tem feito em pesquisa tecnológica. Desde o aparato jurídico, com publicação de várias normas (Lei de Inovação - 10.973/04- Lei do "Bem” -11.196/05- Lei de Propriedade Intelectual - 9.279/96) até a organização interna

do mercado e das indústrias (clusters) e do apoio dos núcleos universitários tem demonstrado um crescente interesse do Estado em organizar seu próprio método para alcançar o desenvolvimento tecnológico. Sem contar os comandos constitucionais dos artigos 218 e 219 da Constituição Federal, que apontam para o protagonismo do Estado no sentido de "promover" e "incentivar" a atuação da iniciativa privada e a necessidade de centralização dos centros de decisão, assim como a endogeneização da economia.

Mesmo diante da evolução e todos os esforços no sentido de incentivar a pesquisa tecnológica, o Brasil continua a ocupar posição de dependência no quadro mundial de comércio.

É preciso muito mais que um acelerado processo de industrialização para efetivar o progresso brasileiro. Celso Furtado e tantos outros autores aqui citados apontam como caminho para superação do subdesenvolvimento a construção da endogeneização tecnológica no país (mercado deve atender prioritariamente a uma demanda nacional) e o combate à heterogeneidade social com vistas a um projeto mais claro de autonomia tecnológica.

Acrescente-se a isso, a necessidade de uma desburocratização da sistemática das industrias, tanto para conseguirem incentivos governamentais (Lei do Bem), quanto para pulverizarem novas descobertas e invenções no mercado nacional.

Dessa forma, a análise feita para construção de autonomia cientifica e tecnológica no Brasil, não representa uma quimera: ao contrário, configura como um roteiro possível dentro das condições desenhadas pelos artigos 218 e 219 da Constituição Federal.

E neste sentido, é possível constatar que na tarefa de endogeneizar a tecnologia na condição periférica e viabilizar a ruptura com o domínio internacional na condição nacional de mercado exige-se uma atuação preponderante do Estado no incentivo às empresas e universidades, na implementação de políticas públicas de ciência e tecnologia e até mesmo na execução de medidas que diminuam as importações de bens e serviços de países centrais. 


\section{REFERÊNCIAS}

ALBUQUERQUE, E.M. Propriedade Intelectual e estratégias para o desenvolvimento. In: VILLARES, F. (org.). Propriedade Intelectual: tensões entre o capital e a sociedade. São Paulo: Paz e Terra, 2007. - "Inadequacy of technology" and innovation systems ate the periphery: notes on Celso Furtado's contributions for a dialogue between evolutionists and structuralists Texto para discussão n. 254. UFMG/Cedeplar. Belo Horizonte, 2005.

AMSDEM, A. H. A Ascenção do "Resto”. São Paulo: Editoria UNESP, 2009.

BERCOVICI, Gilberto; OCTAVIANI, Alessandro; BRAGA, Marco; VASCONCELOS, Jonnas. O Ordenamento da Inovação Tecnológica em Ação: Lei 10.973/04, Lei 11.196/05 e Lei 11.487/07. 2011. Texto gentilmente cedido pelo autor.

BRASIL. Constituição Federal de 1988.

. Lei 9.279/96. Regula direitos e obrigações relativos à propriedade industrial. Diário Oficial da União, de 15. Mai. 1996.

. Lei 10.973/04. Dispõe sobre incentivos à inovação e à pesquisa científica e tecnológica no ambiente produtivo e dá outras providências. Diário Oficial da União de 3.12.2004 e retificado em 16.5.2005.

. Lei 11.196/05 (Lei do Bem). Dispõe sobre incentivos fiscais para a inovação tecnológica e dá outras providências. Diário Oficial da União, de 22. Nov. 2005.

. Lei 11.487/07. Altera a Lei no 11.196, de 21 de novembro de 2005, para incluir novo incentivo à inovação tecnológica e modificar as regras relativas à amortização acelerada para investimentos vinculados a pesquisa e ao desenvolvimento. Diário Oficial da União, de 15. Mai. 2007. 
- Ministério do Desenvolvimento Indústria e Comércio Exterior. Programa Innovate In Brasil. Disponível em: <http://www.innovateinbrasil.com.br>. Acesso em: 06. Jun. 2015.

CABRAL. Anne Cristine. A Constituição e os caminhos para a autonomia tecnológica: uma abordagem entre estruturalistas e evolucionistas. Revista da Faculdade Mineira de Direito, v.15, n. 30, jul./dez. 2012. Disponível em <http://periodicos.pucminas.br/index.php/Direito/ article/viewFile/P.2318-7999.2012v15n30p3/4663>. Acesso em 06 jun.2015.

EM DISCUSSÃO: REVISTA DE AUDIÊNCIA PÚBLICA DO SENADO FEDERAL. Brasília, Senado Federal. Ano 03, nº 12, setembro de 2012, apud TEIXEIRA, Rodrigo de Araújo Teles. $2^{o}$ Painel: Mecanismos de financiamento e participação privada para a pesquisa científica e tecnológica. In: Seminário Caminhos para Inovação. Confederação Nacional da Indústria com organização das Nações Unidas para a Educação, a Ciência e a Cultura (Unesco); e Ministério da Ciência, Tecnologia e Inovação. Senado Federal. Brasília, 2012. Disponível em: <http://www.senado.gov.br/NOTICIAS/JORNALEMDISCUSSAO/upload/201203\%0-\%20s etembro/pdf/em\%20di scuss\%C3\%A3o!_setembro_2012_internet.pdf $>$. Acesso em 05 jun. 2015.

FURTADO, Celso. Desenvolvimento e Subdesenvolvimento. Rio de Janeiro: Contraponto: Centro Internacional Celso Furtado, 2009.

GRAU, Eros. A Ordem Econômica na Constituição de 1988. 12ª Edição. Editora Malheiros: São Paulo, 2007.

KONDER, Leandro. Marxismo e alienação: contribuição para um estudo do conceito marxista de alienação. São Paulo: Expressão Popular, 2009.

OCTAVIANI, A. S. O Ordenamento da inovação tecnológica: a economia política da forma jurídica. Disponível em: 〈http://www.ideiad.com.br/seminariointernacional/a rquivo22.pdf〉, 2008. Acesso em 06 jun.2015. 
A bênção de Hamilton na semiperiferia: ordem econômico-social e os juros da dívida pública interna. In: SCAFF. Fernando Facury. CONTI. José Maurício. (Orgs.). Orçamentos Públicos e Direito Financeiro. Editora: Revista dos Tribunais, São Paulo, 2011.

- Recursos Genéticos e Desenvolvimento: Os desafios furtadiano e gramsciano. Tese de Doutorado. USP. São Paulo, 2008. Disponível em: <http://www.teses.usp.br/teses/disponiveis/2/2133/tde-06112008-081758/pt-br.php>. Acesso em 10 abr.2016.

\section{ORGANIZAÇÃO PARA A COOPERAÇÃO E DESENVOLVIMENTO ECONÔMICO-}

(OCDE). Manual de Oslo: diretrizes para a coleta a interpretação de dados sobre a inovação. $3^{\mathrm{a}}$ ed. 2005.

SCHUMPETER, J. A. Capitalismo, socialismo e democracia. Rio de Janeiro: Fundo de Cultura, 1961.

VILLELA, Taís Nasser. Abordagem Histórica do Sistema Nacional de Inovação e o Papel das Incubadoras de Empresas na Interação com Agentes deste Sistema. XIX Seminário Nacional de Parques Tecnológicos e Incubadoras de Empresas, 2009. Disponível em: <http://www.redetec.org.br/publique/media/PUC-Rio-T-2_1.pdf> Acesso em: 06 jun.2015. 